WOOD

FLAMING

METHANE

BENZENE

ANALYSIS
COMBUSTION

GLOWING

ETHYLENE

ACETYLENE

EMISSIONS

Open access revised manuscript version of

Journal of analytical and applied pyrolysis 71 (2004) 847-854

Link to publisher: doi:10.1016/j.jaap.2003.11.003

\title{
Specific volatile hydrocarbons in smoke from oxidative pyrolysis of softwood pellets
}

Maria Olsson, Olle Ramnäs and Göran Petersson

Further aspects on pellets as biofuel in Sweden are given in chimney emissions from residential pellets burning 


\title{
Specific volatile hydrocarbons in smoke from oxidative pyrolysis of softwood pellets
}

\author{
Maria Olsson, Olle Ramnäs, Göran Petersson* \\ Chemical Environmental Science, Department of Chemical Engineering and Environmental \\ Science, Chalmers University of Technology, SE-41296 Göteborg, Sweden
}

\begin{abstract}
Samples of smoke from laboratory burning of commercial sawdust-based softwood pellets were analysed by gas chromatography on an aluminium oxide column. Flaming burning was very efficient. Significant emitted hydrocarbons were methane, quantitatively followed by ethene and lower proportions of ethane, ethyne and propene. The even lower hydrocarbon emissions from final glowing combustion were strikingly different with ethyne and benzene as the only prominent non-methane hydrocarbons. Smouldering combustion caused much higher hydrocarbon concentrations. Prominent non-methane compounds were furan and ethene from initial smouldering, and ethane, ethene and benzene from after-flame smouldering. The large differences in the proportions of specific hydrocarbons should be considered in evaluations of emissions from residential burning of pellets, with respect to combustion technology and impact on environment and health.
\end{abstract}

Keywords: Methane; Ethene; Propene; 1,3-Butadiene; Benzene; Wood pellets; Combustion; Gas chromatography 


\section{Introduction}

The great potential of wood pellets as a reformulated biofuel was recently manifested by the first international conference on fuel pellets in Stockholm, Sweden, with a large number of scientific and technical contributions [1].

The use of softwood pellets as a renewable fuel for residential heating has increased rapidly during the past few years in northern countries such as Sweden [2]. The pellets are produced mainly from sawdust and wood shavings. Although the emissions are much lower than those from traditional firewood burning, they are important to characterise because pellet burners and stoves are heating options in urban areas [3]. Emission data for a wide range of organic compounds in smoke from wood burning in residential fireplaces are available for comparisons $[4,5,6]$.

Emissions of aromatic hydrocarbons and phenols from softwood pellets have previously been studied both by laboratory burning [7] and by analysis of chimney smoke [2]. Volatile and aromatic hydrocarbons released from pellet ember were reported in a study of glowing charcoal [8]. The purpose of the continued research reported here was to determine the relative proportions of specific volatile hydrocarbons for different combustion stages of softwood pellets. A further aim was comparison with the concentrations of methane, carbon monoxide and carbon dioxide.

The analytical gas chromatographic approach was similar to that used in previous studies of hydrocarbons from burning of wood [4] and other biomass materials [9]. The analytical system was modified to permit simultaneous determination of both methane and $\mathrm{C}_{2}-\mathrm{C}_{7}$ hydrocarbons in gaseous samples.

\section{Experimental}

\subsection{Pellets and burning conditions}

The commercial pellets studied under laboratory burning conditions were obtained from AB Forssjö Bruk, Katrineholm, with a production exceeding 50000 tonnes yearly. The raw material is mainly disintegrated and dried sawdust from Scots pine (Pinus sylvestris) and Norway spruce (Picea abies). The production by pressure extrusion heats the material to more than $100^{\circ} \mathrm{C}$. The pellets had a water content of $8 \%$ and a density of $1.1 \mathrm{~g} / \mathrm{cm}^{3}$. They were 8 $\mathrm{mm}$ in diameter and 10-30 $\mathrm{mm}$ long.

The equipment illustrated in Fig. 1 was used for our laboratory burning experiments in a fume cupboard. Pellets were placed on a steel net under a $20 \mathrm{~cm}$ high aluminium sheet cone, with bottom and top diameters of $10 \mathrm{~cm}$ and $3 \mathrm{~cm}$. Three pellets were set aflame from below 
using a butane torch, and three additional pellets were added subsequently. During burning, air moved freely from below through the net and the cone. The pellets retained their integrity throughout the burning cycle. All samples were collected inside the top of the cone, using a single $100 \mathrm{ml}$ gas-tight glass syringe: To increase low smoke concentrations from final glowing, the top opening of the cone was made smaller.
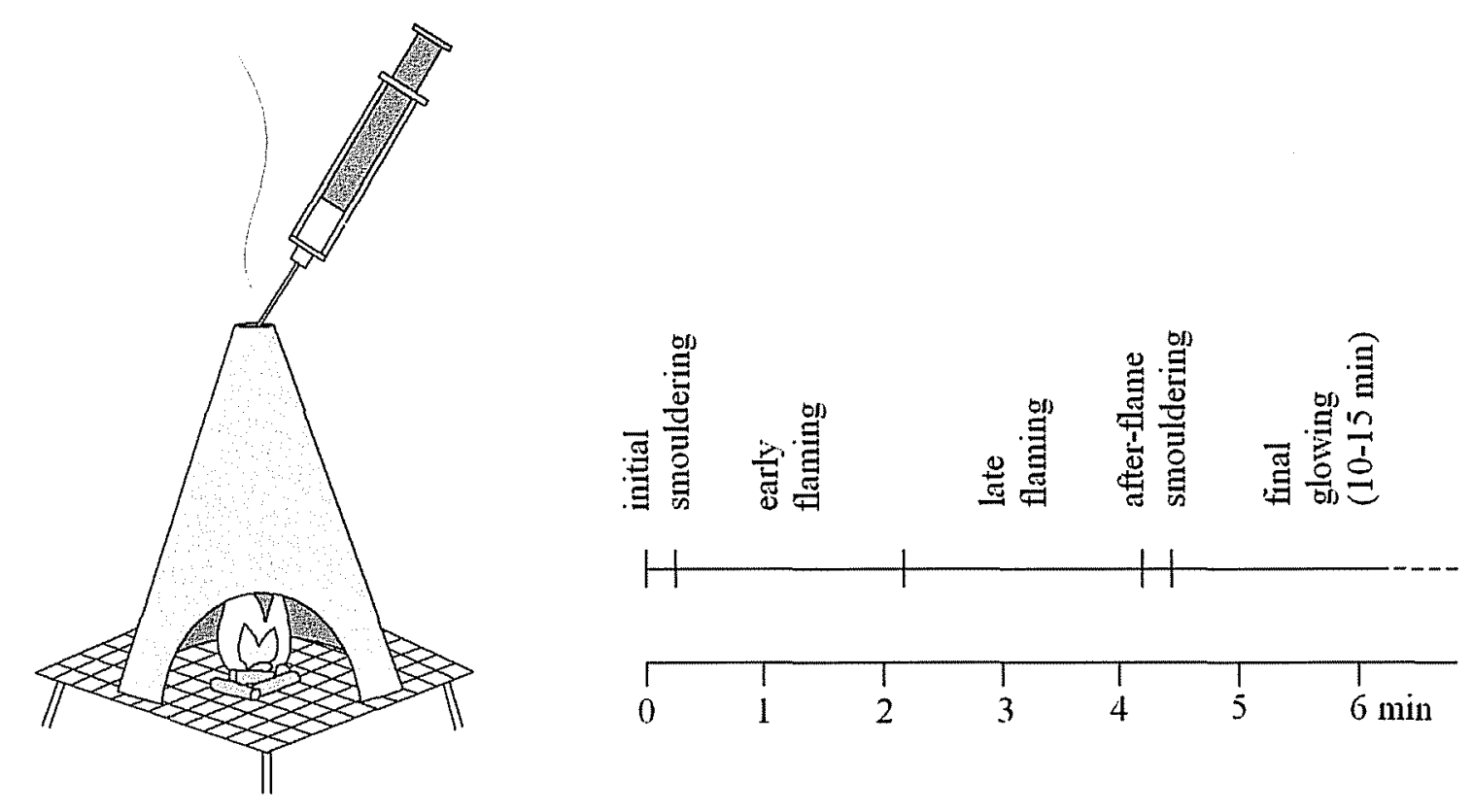

Fig. 1. Laboratory burning and gas sampling device. Time sequence of studied combustion stages.

In Fig. 1, the time sequence of the five investigated combustion stages is illustrated. Samples of smoke from initial smouldering were taken following gentle ignition and addition of more pellets, causing extinguished flaming. Early flaming and late flaming samples were taken early and late during the $5 \mathrm{~min}$ long full flaming combustion period. After-flame smouldering samples caught the smoke evolved immediately after complete vanishing of the flames. Final glowing continued for more than $10 \mathrm{~min}$, and the samples correspond to interior glowing, after gentle blowing to remove all black surfaces of the pellets.

The temperature measured between the pellets with a thermo-couple was $400-500^{\circ} \mathrm{C}$ during early flaming, and fluctuating around $500^{\circ} \mathrm{C}$ during late flaming and after-flame smouldering. The proportions of biomass lost during and remaining after flaming burning were determined by weighing. 


\subsection{Analytical data}

\subsubsection{Volatile hydrocarbons}
Smoke samples
: Taken using a gas-tight $100 \mathrm{ml}$ glass syringe
Sample injection
: Gas sampling valve with a $3.23 \mathrm{ml}$ sampling loop
Gas chromatograph
: Varian 3400 with He as carrier gas, $2 \mathrm{ml} \mathrm{min}^{-1}$
Column
: Open tubular $50 \mathrm{~m} \times 0.32 \mathrm{~mm}$ i.d. fused silica, Chrompack
Stationary phase
: $\mathrm{Al}_{2} \mathrm{O}_{3} / 5 \% \mathrm{KCl}$
Oven temperature
: Increased by $15^{\circ} \mathrm{C} \min ^{-1}$ from $-20^{\circ} \mathrm{C}(2 \mathrm{~min})$ to $100^{\circ} \mathrm{C}$, and by $10^{\circ} \mathrm{C} \mathrm{min}^{-1}$ from $100^{\circ} \mathrm{C}$ to $200^{\circ} \mathrm{C}$ (30 min isothermal)
Detector
: Flame ionisation, with make-up $\mathrm{N}_{2}$
Quantitative proportions : Determined from integrated peak areas in the chromatograms
Absolute response
: Determined using propane as reference gas and set equal (1.0) for all hydrocarbons, and to 0.6 for furan
Identifications
: By comparisons with previous studies $[4,10]$

\subsubsection{Carbon monoxide and carbon dioxide}



\section{Results and discussion}

The results given in Tables 1 and 2 compare the smoke composition of the five combustion stages studied for softwood pellets. The flaming phases represent $80-85 \%$ of the dry biomass burnt and the glowing phase the remaining 15-20\%. Initial and after-flame smouldering may be regarded as transition phases of considerable interest with respect to emissions from different pellet burning devices.

\subsection{Methane and carbon monoxide}

As seen from the results in Table 1, the flaming combustion is very efficient with extremely low concentrations of carbon monoxide and volatile hydrocarbons relative to the comparatively high levels of carbon dioxide. A weight ratio lower than $0.01 \%$ was actually observed between methane and carbon dioxide. The combustion efficiency exceeds $99 \%$, although only a few pellets were burning freely on a net in a laboratory cupboard. 
Table 1. Concentrations ( $\mathrm{mg} \mathrm{m}^{-3}$ ) of major smoke components from different stages of laboratory burning of softwood pellets. The combustion efficiency is reported as the volume ratio $\mathrm{CO}_{2} /\left(\mathrm{CO}+\mathrm{CO}_{2}\right)$. The results are given as averages of six samples for each stage.

\begin{tabular}{lcccccc}
\hline & $\begin{array}{c}\text { Initial } \\
\text { smouldering }\end{array}$ & $\begin{array}{c}\text { Early } \\
\text { flaming }\end{array}$ & $\begin{array}{c}\text { Late } \\
\text { flaming }\end{array}$ & $\begin{array}{c}\text { After-flame } \\
\text { smouldering }\end{array}$ & $\begin{array}{c}\text { Final } \\
\text { glowing }\end{array}$ \\
\hline Carbon dioxide & $4400 \pm 2000$ & $56000 \pm 30000$ & $110000 \pm 30000$ & $18000 \pm 7000$ & $23000 \pm 1000$ \\
Carbon monoxide & $530 \pm 290$ & $120 \pm 110$ & $160 \pm 90$ & $2400 \pm 1200$ & $1300 \pm 400$ \\
Methane & $11 \pm 5$ & $2.6 \pm 1.5$ & $7.3 \pm 5.0$ & $200 \pm 100$ & $3.1 \pm 1.5$ \\
Non-methane hydrocarbons & $28 \pm 14$ & $3.4 \pm 2.4$ & $3.4 \pm 1.2$ & $52 \pm 29$ & $1.7 \pm 0.3$ \\
\hline Combustion efficiency (\%) & $84.5 \pm 6.3$ & $99.7 \pm 0.2$ & $99.7 \pm 0.2$ & $81.9 \pm 3.1$ & $91.7 \pm 2.8$ \\
\hline
\end{tabular}

In sharp contrast, the proportion of carbon monoxide is much higher for glowing combustion, with a combustion efficiency of only $90 \%$. The hydrocarbon levels are very low for glowing combustion. The formation of methane relative to carbon dioxide appears to be between one and two orders of magnitude lower for glowing pellets than for firewood ember [8]. This surprising result is ascribed to the small compressed sawdust-derived particles in pellets, causing differing gas diffusion and heat transfer characteristics [11].

The smouldering transition phases represent combustion efficiencies as low as about $80 \%$. The concentrations of methane and other volatile hydrocarbons, relative to carbon dioxide, are also much higher than for both flaming and glowing combustion. Oxygen-free pyrolysis converts as much as $1 \%$ of the dry biomass of wood pellets to methane [12]. Semi-volatile lignin-related 2-methoxyphenols are major compounds released on burning of softwood pellets with limited air supply, as reported in a previous study [7]. Their concentration in similarly analysed smoke from the now studied initial smouldering exceeded that of methane by one order of magnitude. In sharp contrast, methoxyphenols were almost absent in smoke from flaming combustion and after-flame smouldering and glowing.

Pellet burning in residential appliances represents a mixture of mainly flaming, less glowing and very little smouldering combustion. Combustion efficiencies of 96-100\%, and methane to carbon dioxide ratios lower than $0.1 \%$ were observed for chimney samples from different devices [2]. Methoxyphenols were assessed in smoke from pellet stoves, but in concentrations one order of magnitude lower than that of methane [2].

\subsection{Non-methane hydrocarbons}

In Table 2, average relative proportions are given for recorded non-methane volatile compounds of particular significance in smoke from the five combustion stages. The total concentration of non-methane hydrocarbons in Table 1 refers to these seven hydrocarbons and furan. 
Table 2. Proportions (\%) of prominent non-methane hydrocarbons and furan in smoke from laboratory burning of softwood pellets (averages and standard deviations of six samples from each combustion stage).

\begin{tabular}{lccccc}
\hline & $\begin{array}{c}\text { Initial } \\
\text { smouldering }\end{array}$ & $\begin{array}{c}\text { Early } \\
\text { flaming }\end{array}$ & $\begin{array}{c}\text { Late } \\
\text { flaming }\end{array}$ & $\begin{array}{c}\text { After-flame } \\
\text { smouldering }\end{array}$ & $\begin{array}{c}\text { Final } \\
\text { glowing }\end{array}$ \\
\hline Ethane & $12.5 \pm 2.1$ & $11.6 \pm 1.4$ & $19.6 \pm 8.2$ & $37.8 \pm 6.2$ & 0.0 \\
Ethene & $26.5 \pm 3.6$ & $44.7 \pm 3.1$ & $46.9 \pm 6.0$ & $21.7 \pm 1.9$ & $2.0 \pm 1.6$ \\
Propene & $14.7 \pm 1.7$ & $9.2 \pm 1.3$ & $9.2 \pm 1.2$ & $6.6 \pm 4.6$ & 0.0 \\
Ethyne & $5.8 \pm 3.3$ & $22.8 \pm 1.3$ & $14.6 \pm 4.7$ & $3.4 \pm 1.5$ & $67.9 \pm 8.2$ \\
1,3-Butadiene & $4.1 \pm 0.4$ & $2.1 \pm 1.0$ & $1.2 \pm 0.3$ & $0.4 \pm 0.5$ & 0.0 \\
Furan & $30.7 \pm 4.7$ & $5.0 \pm 2.7$ & $2.8 \pm 0.9$ & $0.6 \pm 0.8$ & 0.0 \\
Benzene & $3.0 \pm 1.1$ & $3.4 \pm 1.8$ & $5.2 \pm 2.9$ & $22.6 \pm 10.4$ & $30.2 \pm 6.7$ \\
Methylbenzene & $2.7 \pm 0.4$ & $1.2 \pm 1.0$ & $0.7 \pm 1.2$ & $7.0 \pm 1.0$ & 0.0 \\
\hline
\end{tabular}

In smoke from flaming burning, the concentrations of hydrocarbons were remarkably low. Ethene constituted almost half of the non-methane hydrocarbons. Ethyne, propene and benzene were other significant unsaturated hydrocarbons. The proportions between the hydrocarbons were similar to those reported for smoke from fireplace burning of pinewood $[5,6]$, but the concentrations relative to carbon dioxide are one order of magnitude lower. Late flaming differed from early flaming by higher proportions of the saturated hydrocarbons methane (Table 1) and ethane (Table 2).

The hydrocarbon emissions from final glowing combustion in the interior of the pellets were very low, but strikingly different in composition. The only significant non-methane hydrocarbons were ethyne and benzene in an approximate 2:1 proportion. Compared to flaming combustion, the concentrations of these compounds also increased relative to methane. The charcoal character of the glowing pellets with a low $\mathrm{H} / \mathrm{C}$ ratio may explain the formation of the two hydrocarbons which both have a low $1: 1 \mathrm{H} / \mathrm{C}$ ratio. Contributing reasons may be high thermal stabilities and low reactivities towards oxygen radicals of both ethyne and benzene. In sharp contrast with pellets, glowing firewood emits specific hydrocarbons in similar proportions as flaming firewood [4].

The initial and after-flame smouldering transition phases differ from flaming and glowing burning by much higher hydrocarbon concentrations and differing hydrocarbon proportions. The initial smouldering reflects pyrolysis of the original softwood with high proportions of furan formed from cellulose and other polysaccharides. The proportion of ethene was high relative to methane and carbon dioxide in accordance with results observed for smouldering of ground pinewood [13]. The smoke released immediately after spontaneously extinguished 
flames originates from softwood remainders after extensive gasification. The proportions of methane, ethane and benzene increased relative to initial smouldering whereas the proportions of the more reactive components furan, propene and 1,3-butadiene decreased. Significant emissions from smouldering combustion of pellets are likely to occur mainly from improperly functioning pellet stoves.

From Table 1, it is evident that the ratio between non-methane hydrocarbons and carbon dioxide ranges from 0.00001 for flaming and glowing to 0.001 for smouldering. A similar wide range, but with at least tenfold higher hydrocarbon proportions, has been observed for burning of solid wood and other biomass materials [4]. The less efficient burning of solid wood relative to wood pellets also produces a much larger number of specific hydrocarbons and other compounds in significant amounts [5,6]. Differences between flaming and smouldering have been reported in combustion efficiency of foliar fuels [14] and in proportions between specific volatile hydrocarbons from wood-related biomass fuels [4]. Detailed specification of smoke components normally refers to only one averaged section of the burning cycle $[5,6,13,14]$. The results for wood pellets suggest that studies of smoke from different combustion stages are of interest for other biofuels as well.

\subsection{Analytical performance}

The chromatogram in Fig. 2 illustrates the separation of the reported volatile hydrocarbons, including methane and furan. One of the samples from initial smouldering was chosen because all reported and a few additional compounds are present in significant amounts.

Methane is eluted almost without retention as a broad peak, reflecting the fairly large injected smoke volume. The subsequent ethane peak is broad for the same reason. Methane, ethane and ethene are eluted at low temperatures outside the normal operating range of the column. The other reported compounds appear later in the order propene, ethyne, 1,3butadiene, furan, benzene and methylbenzene. The aromatic compounds are eluted during the final isothermal part of the oven temperature program. The temperature rise from $-20^{\circ} \mathrm{C}$ to $200^{\circ} \mathrm{C}$ during the time period 2-20 min explains the observed baseline drift. 


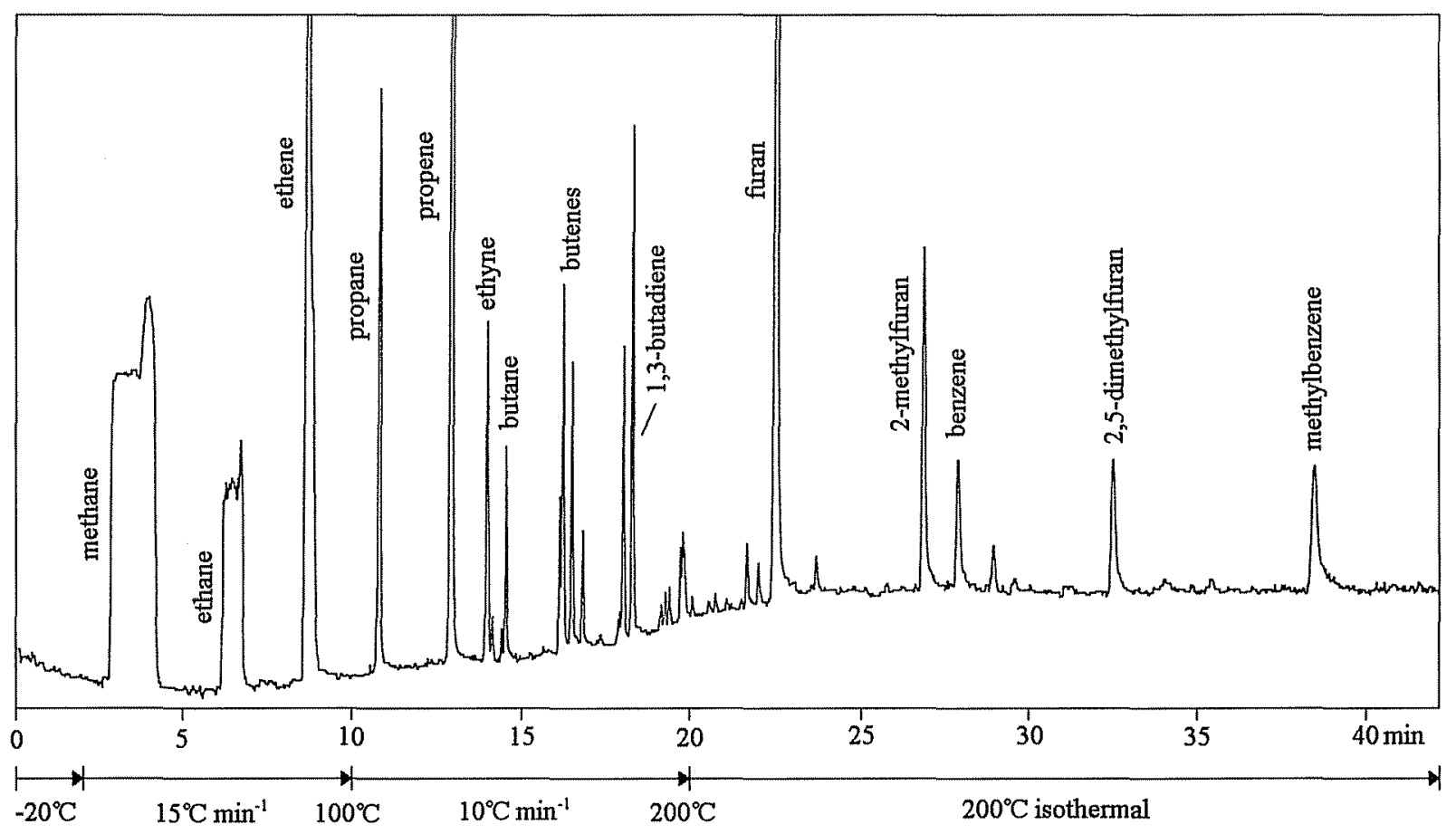

Fig. 2. Gas chromatographic separation of $\mathrm{C}_{1}-\mathrm{C}_{7}$ volatile hydrocarbons and furans from the initial smouldering phase during laboratory burning of softwood pellets.

The large proportion of furan from initial smouldering was accompanied by significant proportions of 2-methylfuran and 2,5-dimethylfuran. These furans were negligible in smoke from the other combustion stages. The four butene isomers were also present in much lower proportions in smoke from later combustion stages. The quantitative ratio between ethane and propane was about 3:1 and almost independent of combustion conditions. The formation of butane was almost negligible, even during the initial smouldering, and no significant contributions were observed from the butane torch used for igniting the pellets.

The analytical aluminium oxide column permits selective determination of volatile hydrocarbons [9] and furans [10] from wood burning. More polar volatile compounds are irreversibly retained on the column. Our previous studies of volatile $\mathrm{C}_{2}-\mathrm{C}_{8}$ hydrocarbons in wood smoke were based on the use of adsorbent sampling cartridges [4]. The present study demonstrates the favourable simultaneous determination of methane and other volatile hydrocarbons in directly injected gaseous samples.

\subsection{Biofuel conclusions}

The volatile hydrocarbons differ very much in concentrations and relative proportions in smoke from different combustion stages of softwood pellets. The emissions of non-methane 
hydrocarbons from flaming and final glowing combustion are almost negligible compared to those from solid firewood burning. The emissions on ignition and shortly after flame fade-out are much larger. Obviously, it is important that pellet burning devices are constructed to avoid unnecessary emissions from fluctuations between different burning stages. Increased emissions have been observed from certain appliances when operated on low effect [2]. Improved combustion options would make urban residential heating with wood pellets even less objectionable than before with respect to air pollutants.

The very low emissions from wood pellets relative to solid firewood and other solid biofuels can hardly be explained only by their low water content and uniform shape. The hydrocarbon emissions from glowing pellets are as low as those from good quality grilling charcoal [8]. They are much lower and very different in composition relative to those of solid wood ember [4]. It can be concluded that the fine particle structure of the pellets significantly improves their combustion characteristics and decreases emissions to air.

The much lower hydrocarbon emissions from burning of wood pellets compared to solid firewood gives several environmental advantages. An increased advantage with respect to the greenhouse effect is obtained because of the low methane emissions compared to biomass burning in general [15]. The contribution to global warming of methane from residential burning of pellets appears to be less than $0.1 \%$ of the carbon dioxide contribution saved by the biofuel [2]. The contribution to photooxidant formation in the summer season is low because of low emissions of ethene and propene as the most important ozone precursors [16] in the smoke. The four most significant hydrocarbons with respect to health hazards are ethene, propene, benzene and 1,3-butadiene [17] which are emitted from burning of all solid biomass fuels [9] but only in very small amounts from wood pellets.

\section{Acknowledgement}

The financial support of the Swedish Energy Agency is gratefully acknowledged.

\section{References}

[1] Proceedings of "The First World Conference on Pellets", Stockholm, Sweden, Sept 2-4, 2002, www.pellets2002.com.

[2] M. Olsson, J. Kjällstrand, G. Petersson, Biomass Bioenergy 24 (2003) 51-57.

[3] C. Boman, A. Nordin, L. Thaning, Biomass Bioenergy 24 (2003) 465-474.

[4] G. Barrefors, G. Petersson, Chemosphere 30 (1995) 1551-1556.

[5] J. J. Schauer, M. J. Kleeman, G. R. Cass, B. R. T. Simoneit, Environ. Sci. Technol. 35 
(2001) 1716-1728.

[6] J. D. McDonald, B. Zielinska, E. M. Fujita, J. C. Sagebiel, J. C. Chow, J. G. Watson, Environ. Sci. Technol. 34 (2000) 2080-2091.

[7] M. Olsson, J. Kjällstrand, G. Petersson, J. Anal. Appl. Pyrolysis 67 (2003) 135-141.

[8] M. Olsson, G. Petersson, Sci. Total Environ. 303 (2003) 215-220.

[9] G. Barrefors, G. Petersson, J. Chromatogr. A 710 (1995) 71-77.

[10] G. Barrefors, S. Björkqvist, O. Ramnäs, G. Petersson, J. Chromatogr. A 753 (1996) 151155.

[11] J. Larfeldt, B. Leckner, M. C. Melaaen, Biomass Bioenergy 18 (2000) 507-514.

[12] W. de Jong, A. Pirone, M. A. Wójtowicz, Fuel 82 (2003) 1-9.

[13] L. M. McKenzie, W. M. Hao, G. N. Rickards, D. E. Ward, Atmos. Environ. 28 (1994) 3285-3293.

[14] M. D. Hays, C. D. Geron, K. J. Linna, N. D. Smith, J. J. Schauer, Environ. Sci. Technol. 36 (2002) 2281-2295.

[15] R. Delmas, Fert. Res. 37 (1994) 181-190.

[16] R. Atkinson, Atmos. Environ. 24A (1990) 1-41.

[17] M. Törnqvist, L. Ehrenberg, Environ. Health Perspect. 102 (1994) 173-182. 